\title{
Experimental Measurement and Investigation on the Feasibility of Improvement of Physical and Dielectric Properties of Barium Titanate
}

\author{
Chasib KF* \\ Petroleum \& Gas Engineering Department, Collage of Engineering, University of Thi \\ Qar, Iraq \\ *Corresponding author: Khalid Farhod Chasib, Petroleum \& Gas Engineering \\ Department, Collage of Engineering, University of Thi Qar, Thi Qar, Iraq, Tel: 7902 \\ 898 018; Email: khalid_farhod@utq.edu.iq
}

\section{Research Article}

Volume 3 Issue 1

Received Date: March 20, 2019

Published Date: April 01, 2019

DOI: $10.23880 /$ ppej-16000183

\section{Abstract}

Recent research has examined the improvement of physical and dielectric properties of $\mathrm{BaTiO}_{3}$ ceramic material by the small addition of excess $\mathrm{TiO}_{2}$ or $\mathrm{BaCO}_{3}$. The prepared samples sintered at different temperatures and varying soaking time. The results show that increasing the sintering temperature within $\left(1350{ }^{\circ} \mathrm{C}\right)$ and soaking time within $(10 \mathrm{hrs})$ gives better electrical and physical properties, which indicate that the reaction is complete at higher temperature and periods.

Keywords: Barium Titanate; Soaking Time; Sintering Temperature; Dielectric Properties

\section{Introduction}

The inorganic compound Barium titanate $\left(\mathrm{BaTiO}_{3}\right)$ is transparent as larger crystals and white powder with a piezoelectric properties, photorefractive effect and a ferroelectric ceramic material. It is used in electromechanical transducers, nonlinear optics and capacitors.

Piezoelectricity is one property of a group of dielectric materials called ferroelectrics. These materials are characterised by a domain structure that can be modified by an electric field. The piezoelectric effect manifests as a spontaneous potential difference across the opposite faces of a volume of material when under an applied stress. This potential is proportional directly to the mechanical stress applied to it. The inverse is also true, i.e., electric field implementation causes strain in a volume of piezoelectric material [1].

The first piezoelectric material discovered was Calcium Titanate, which has the perovskite structure. A traditional commercial example is Barium titanate, which is commonly used in capacitors and transducers due to its high permittivity [2]. The reaction between $\mathrm{BaCO}_{3}$ and $\mathrm{TiO}_{2}$ proceeds via several intermediate stages of which formation of $\mathrm{BaTiO}_{4}$ is the most distinct. The grain size of $\mathrm{BaTiO}_{3}$ ceramic is controlled by inhibition the grain growth by using an excess amount of $\mathrm{TiO}_{2}$ as a second phase which behaves as inhibitor [3].

By adjusting the $\mathrm{Ba} / \mathrm{Ti}$ ratio it can be obtain the stoichiometric powders, in the powder excess Barium incorporation when higher $\mathrm{Ba} / \mathrm{Ti}$ ratio [4]. With range of 


\section{Petroleum \& Petrochemical Engineering Journal}

stoichiometry 0.995 - 1.00, optimum electric properties and sintering behavior are expected obtained [5].

In hybrid vehicles, electric ships and pulse power systems used widely Energy storage capacitors. Because of applications of electronic systems are lighter demand and smaller, the desired for each capacitor high-energy density, when dielectric constant increase for a linear dielectric, the stored energy density was improves linearly, while electric field develops quadratically. Therefore, a strong interest has created by the drive toward device miniaturization with high dielectric breakdown strength (BDS) in ferroelectric glass-ceramic materials. Glass-ceramics are an almost zero porosity and crystallization possess a uniformity of microstructure and fabricated through controlled nucleation, which supply singular characteristic for capacitor applications at highenergy density, In contrast to the processed ferroelectric ceramics (the conventional powder) [6-9].

Little alteration in porosity, grain size, composition, etc., can considerably alter dielectric materials physical properties. These influences are the ultimate significance for ferroelectric glass-ceramics capacitor applications. Even in the situation of exceedingly investigated Tungsten-Bronze glass-ceramics and perovskite such as strontium bariumniobate (SBN) and barium titanate (BT) these influences away from purified, and strong study efforts are yet underway in order to discovery relationships between dielectric properties, the microstructure (grain morphology, grain size, etc.) and composition. This paper concentrate on tailoring the $\mathrm{BaO}-$ $\mathrm{TiO}_{2}-\mathrm{Al}_{2} \mathrm{O}_{3}-\mathrm{SiO}_{2}$ composition of glass by means of change the ratio of $\mathrm{Ba} / \mathrm{Ti}$ in order to investigate its effect on the crystalline phases, microstructure, and hence the resulting glass-ceramics dielectric properties. Microstructure development, phase developments, detailed thermal analysis, dielectric constant and dielectric BDS, loss spectra were calculated as a function of the ratio of $\mathrm{Ba} / \mathrm{Ti}$. The relationship between the dielectric properties and microstructure was correlated [10-12].

Synthesize Barium titanate by heating barium carbonate and titanium dioxide. These reactions occur by means of sintering of liquid phase. Barium titanate Single crystals can be created from molten potassium fluoride at around $1100^{\circ} \mathrm{C}$. Barium titanate indissoluble in alkalis and water. It is whilst, soluble in various acids such as hydrofluoric acid, hydrochloric acid and sulfuric acid. The compound can melt totally in concentrated sulfuric acid and hydrofluoric acid. Barium titanate is obtainable in crystal forms or powder hich have a perovskite constructing, solid Barium titanate structure may alter with temperature. Five different phases can exist, from high temperature to low temperature. Hexagonal, cubic, orthorhombic, rhombohedral and tetragonal. Ferroelectric characteristic are present by all the phases excluding the cubic phase. Octahedral $\mathrm{TiO}_{6}$ centers are the cubic phase which realizes Ti vertices and a cube with Ti0-Ti edges [13-28].

\section{Experimental Work}

Barium Titanate $\left(\mathrm{BaTiO}_{3}\right)$ is white to grey powder in color and its structure is perovskite. In numerous acids is soluble including hydrochloric, sulfuric and hydrofluoric acids. In alkalis and water its insoluble, an electrical insulator in the pure form. However it becomes semiconducting when doped with little amounts of metals, most notably samarium, neodymium, yttrium, scandium etc [8].

A semiconductor shows positive temperature of resistivity co-efficient (PTCR) properties in the form of polycrystalline. At Curie temperature an raise in resistivity will show various orders of extent, and can controlled by the dopant. Barium titanate Curie temperature suffers change from tetrahedral to cubic phase. Barium titanate monocular crystals show resistivity temperature co-efficient negative (NTCR) properties. it show properties of ferroelectric and is photorefractive material excellent [12].

The piezoceramic material Barium Titanate $\left(\mathrm{BaTiO}_{3}\right)$ was prepared by reacting a suitable grade of $\mathrm{BaCO}_{3}$ with $\mathrm{TiO}_{2}$. These raw materials are weighed out in four different ratio's (1.03/1,1/1,1/1.03, 1/1.003) according to the stoichometric equation below:

$$
\mathrm{BaCO}_{3}+\mathrm{TiO}_{2} \rightarrow \mathrm{BaTiO}_{3}+\mathrm{CO}_{2}
$$

For each run the raw materials mixed and milled in an agate ball mill for $8 \mathrm{hrs}$ and then calcined the result powder at $1200^{\circ} \mathrm{C}$ for $8 \mathrm{hrs}$.

The calcined powder milled and sieved in an 38 ? $\mathrm{m}$ sieve, then weighed a proper amount and press it after mixing with PVA binder, in a rod with $1 \mathrm{~cm}$ diameter using 2.5 ton load. These samples at various temperatures $(1200,1300,1350)^{\circ} \mathrm{C}$ then sintered in air for different periods $(2,4,6,8,10) \mathrm{hrs}$. The bulk density measured and the true porosity is calculated by the relation: 


\section{Petroleum \& Petrochemical Engineering Journal}

$\rho_{\text {bulk }}=\rho_{\mathrm{H}_{2} \mathrm{O}}\left[\frac{\text { dry mass }}{\text { impregnated mass-immersed mass }}\right]$

Since the density of water equal to $1 \mathrm{~g} / \mathrm{cm}^{3}\left(\rho_{\mathrm{H}_{2} \mathrm{O}}=1\right)$, then

$$
\text { T.P } \%=\left[1-\frac{\text { bulk density }}{\text { true density }}\right] \times 100 \%
$$

The true density for $\mathrm{BaTiO}_{3}$ is $6.02 \mathrm{~g} . \mathrm{cm}^{-3}$. [5]

The relative dielectric constant $(\mathrm{K})$ is measured by using LCR meter for the electroded samples:

$$
\mathrm{K}=c \cdot d / \varepsilon_{o} \cdot A
$$

Where

$c$ : capacitance of the prepared samples (Farad).

$d$ : thickness of the sample (m).

$\varepsilon_{0}$ : permittivity of vacuum $=8.85 * 10^{-12} \mathrm{C}^{2} / \mathrm{N} . \mathrm{m}^{2}$.

$A$ : cross-sectional area of samples (m).

\section{Results and Discussion}

\section{Bulk Density}

Results shows that the sintering temperature and soaking time has a remarkable influence on the bulk density of the prepared $\mathrm{BaTiO}_{3}$ for the two $\mathrm{Ba}$ /Ti ratio's as shown in Figures $1 \& 3$. Above $1300{ }^{\circ} \mathrm{C}$ sintering causes discontinuous grain growth by increased diffusion in the liquid phase. A number of different compounds are possible with either excess of $\mathrm{TiO}_{2}$ or $\mathrm{BaCO}_{3}$. Under the condition of excess titania, a liquid phase is formed to enhance sintering and this has been reported experimentally in figures $1 \& 3$ [3].

\section{True Porosity}

Porosity for the sintered $\mathrm{BaTiO}_{3}$ with different sintering temperature and soaking time for the two cases of $\mathrm{Ba} / \mathrm{Ti}(0.997,1.03)$, was calculated in the percentage law using true density of $\mathrm{BaTiO}_{3}$ equal to $6.02 \mathrm{gm} / \mathrm{cm}^{3}$. The percentage true porosity as a function of soaking time is shown in Figures $2 \& 4$.

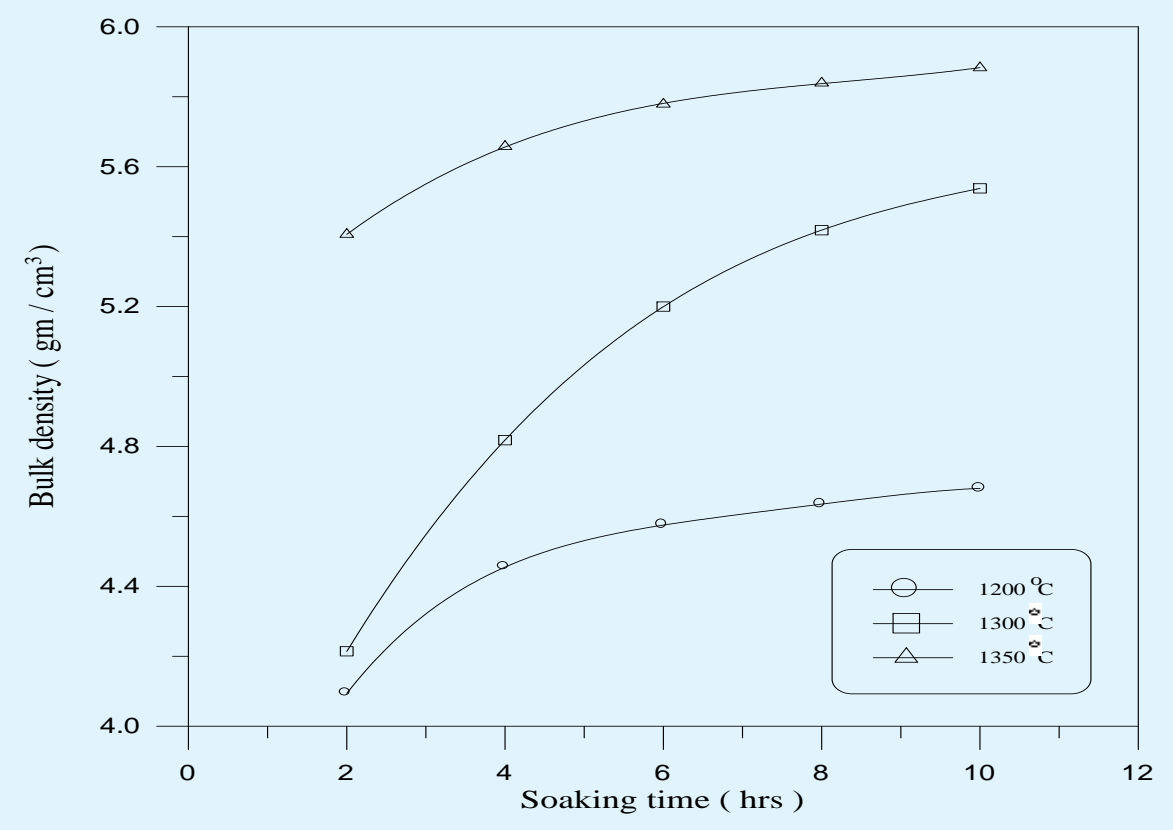

Figure 1: Bulk density of $\mathrm{BaTiO}_{3}$ samples sintered at different temperatures with $\mathrm{Ba} / \mathrm{Ti}=0.997$. 


\section{Petroleum \& Petrochemical Engineering Journal}

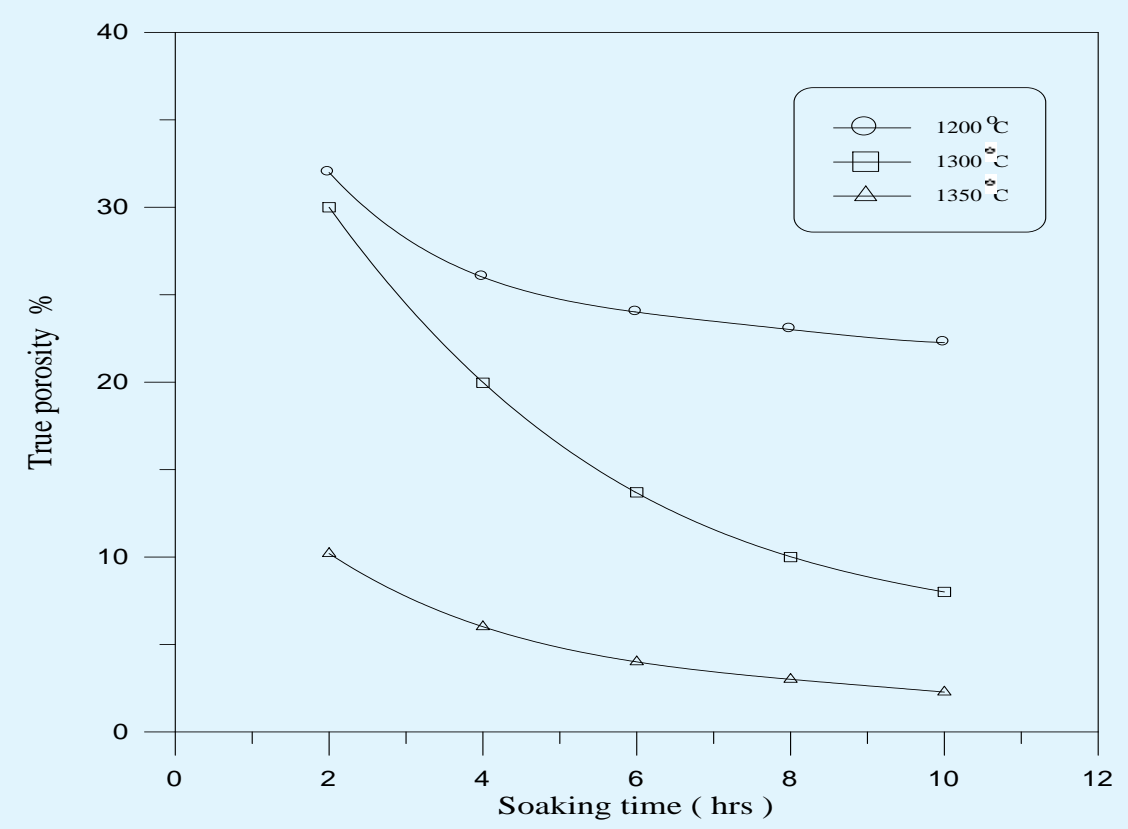

Figure 2: Percentage True porosity of $\mathrm{BaTiO}_{3}$ samples sintered at different temperatures with $\mathrm{Ba} / \mathrm{Ti}=0.997$.

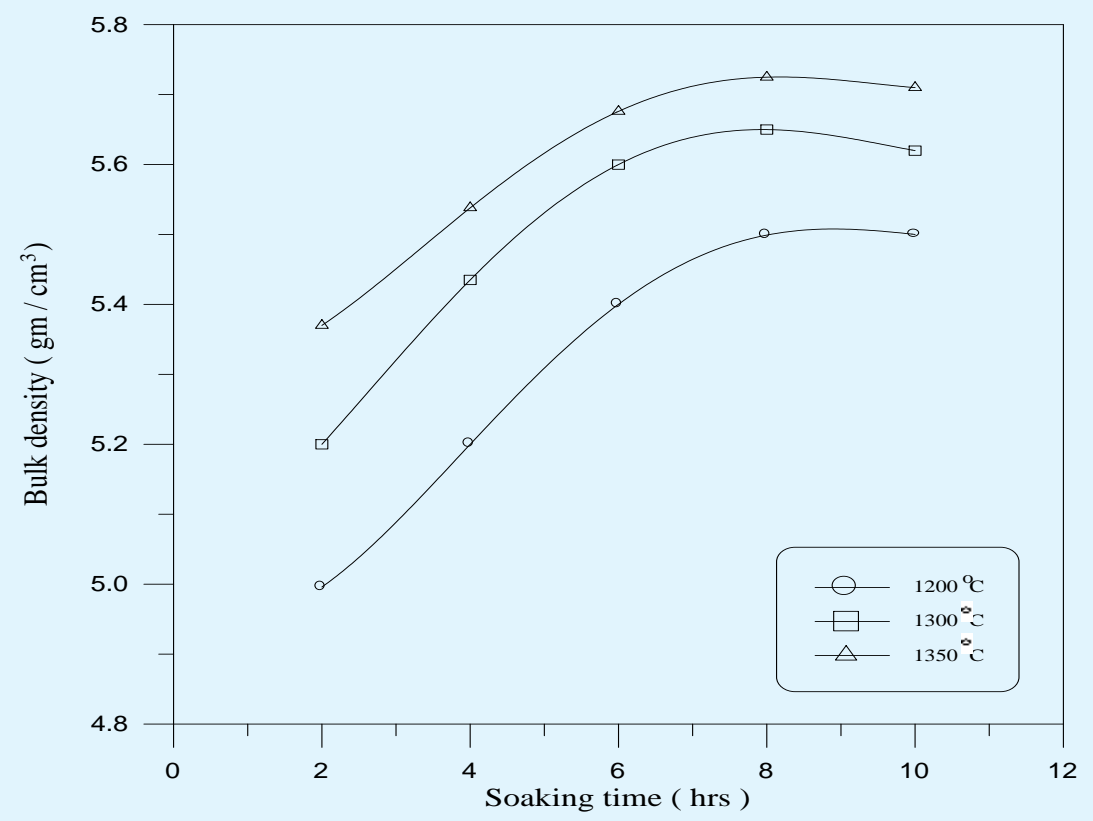

Figure 3: Bulk density of $\mathrm{BaTiO}_{3}$ samples sintered at different temperatures with $\mathrm{Ba} / \mathrm{Ti}=1.03$. 


\section{Petroleum \& Petrochemical Engineering Journal}

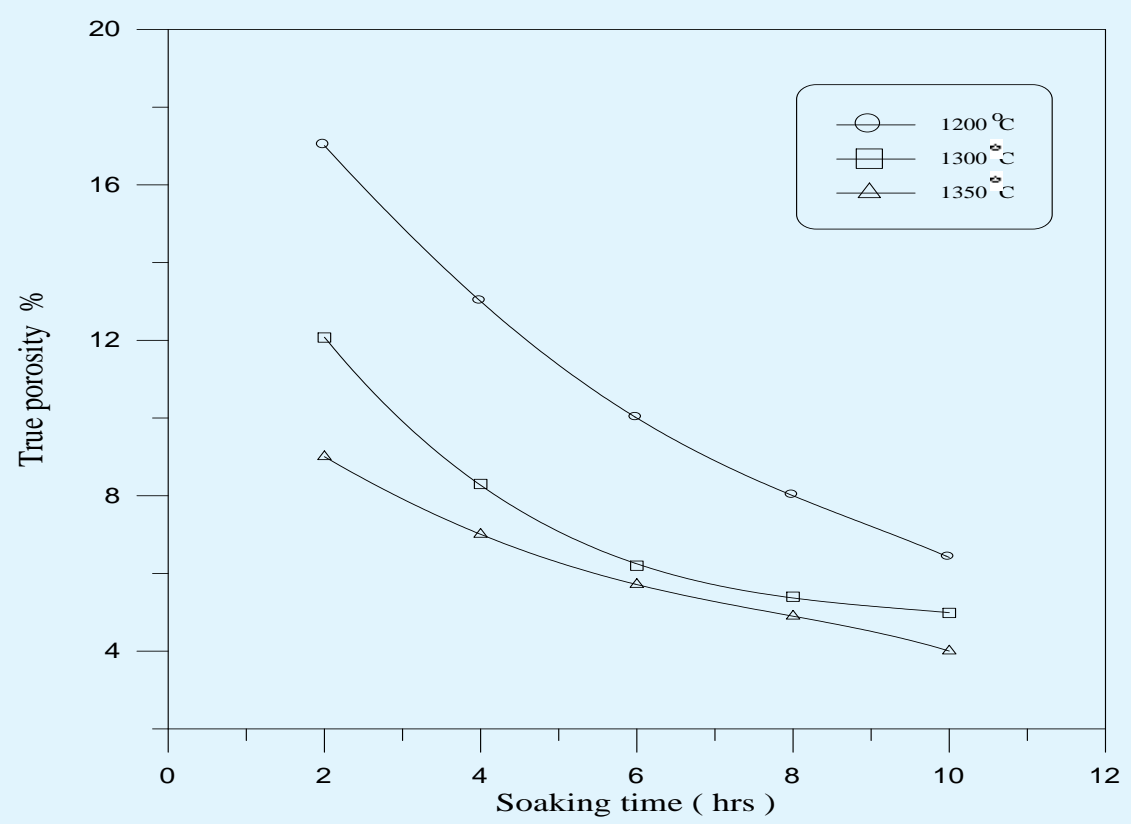

Figure 4: Percentage True porosity of $\mathrm{BaTiO}_{3}$ samples sintered at different temperatures with $\mathrm{Ba} / \mathrm{Ti}=1.03$.

\section{Dielectric Constant}

Dielectric constant of $\mathrm{BaTiO}_{3}$ is extremely sensitive to $\mathrm{Ba} / \mathrm{Ti}$ ratio, and also to the sintering temperature and soaking period as shown in Figures $5 \& 6$, in which the dielectric constant increased as the sintering temperature increased, it reaches a maximum value at $1350^{\circ} \mathrm{C}$ at $(8-10)$ hrs, and it differs slightly after this temperature.

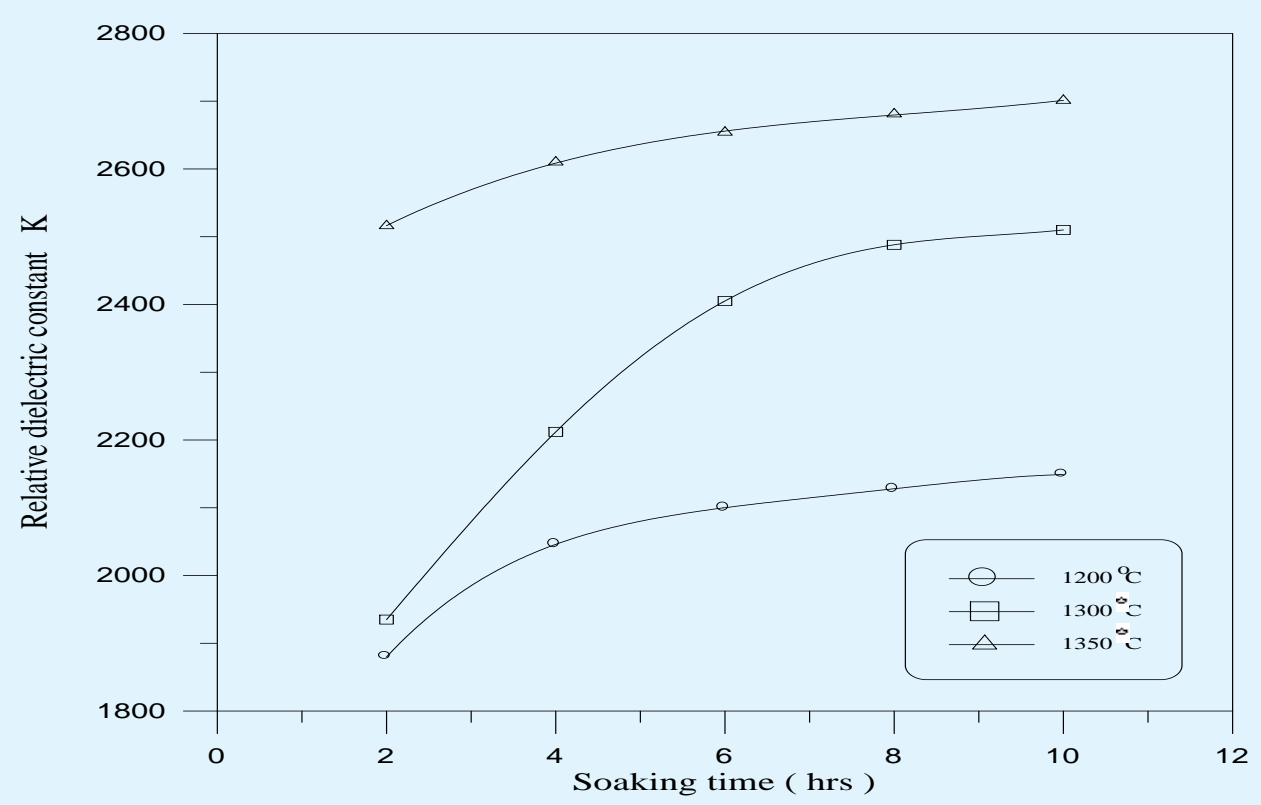

Figure 5: Dielectric constant (measured at $10 \mathrm{KHz}$ ) as a function soaking time for $\mathrm{BaTiO}_{3}$ with $\mathrm{Ba} / \mathrm{Ti}=0.997$. 


\section{Petroleum \& Petrochemical Engineering Journal}

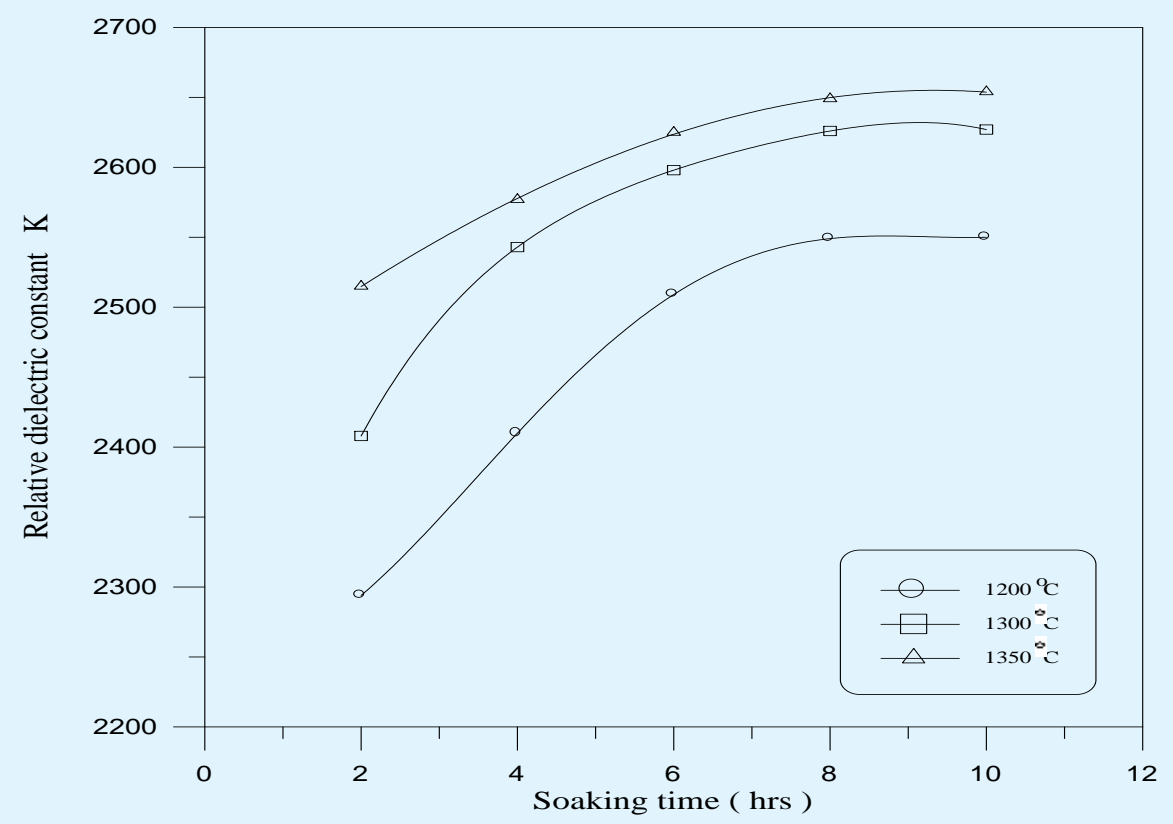

Figure 6: Dielectric constant (measured at $10 \mathrm{KHz}$ ) as a function soaking time for $\mathrm{BaTiO}_{3}$ with $\mathrm{Ba} / \mathrm{Ti}=1.03$.

The temperature at which the spontaneous polarisation disappears is called the Curie temperature, $\mathrm{T}_{\mathrm{C}}$. Above $120^{\circ} \mathrm{C}$, barium titanate has a cubic structure. This means it is centro-symmetric and possesses no spontaneous dipole. With no dipole the material behaves like a simple dielectric, giving a linear polarisation. $\mathrm{T}_{\mathrm{C}}$ for barium titanate is $120^{\circ} \mathrm{C}$.

Below $120^{\circ} \mathrm{C}$, it changes to a tetragonal phase, with an accompanying movement of the atoms. The movement of Ti atoms inside the $\mathrm{O}_{6}$ octahedra may be considered to be significantly responsible for the dipole moment.

Cooling through $120{ }^{\circ} \mathrm{C}$ causes the cubic phase of barium titanate to transform to a tetragonal phase with the lengthening of the lattice parameter. The dipole moment may be considered to arise primarily due to the movement of $\mathrm{Ti}$ atoms with respect to the 0 atoms in the same plane, but the movement of the other 0 atoms (i.e. those $\mathrm{O}$ atoms above and below $\mathrm{Ti}$ atoms) and the $\mathrm{Ba}$ atoms is also relevant

\section{Conclusions}

Sintering below $1350^{\circ} \mathrm{C}$ is advised to prevent production of reaction phases. However, high temperature is required to improve the sintered density by thermal activation. The physical and dielectric properties influence by the $\mathrm{Ba} / \mathrm{Ti}$ ratio, sintering temperature and the soaking time. Increasing $\mathrm{TiO}_{2}$ in a small proportion effect largely the physical and dielectric properties of the resulted piece. Increasing $\mathrm{BaCO}_{3}$ in a quantity larger than that of $\mathrm{TiO}_{2}$ also effect the physical and dielectric properties of $\mathrm{BaTiO}_{3}$. But the small addition of $\mathrm{TiO}_{2}$ effect is more effective than that of larger amount of $\mathrm{BaCO}_{3}$.

\section{References}

1. Xu J, Wong CP (2009) Low-loss percolative dielectric composite. Appl Phys Lett 87: 082907.

2. Arbatti M, Shan X, Cheng ZY (2007) Ceramic-Polymer Composites with High Dielectric Constant. Adv Mater 19(10): 1369-1372.

3. Homes CC, Vogt T (2013) Colossal permittivity materials: Doping for superior dielectrics. Nat Mater 12(9): 782-783.

4. Zhang L, Wu P, Li Y, Cheng ZY, Brewer JC (2014) Preparation process and dielectric properties of Ba0.5Sr0.5TiO3-P(VDF-CTFE) nanocomposites. Compos B Eng 56: 284-289. 


\section{Petroleum \& Petrochemical Engineering Journal}

5. Ring KM, Kavanaph KL (2003) Substrate effects on the ferroelectric properties of fine-grained $\mathrm{BaTiO3}$ films. J Appl Phys 94: 5982.

6. Kumar N, Pan J, Aysha N, Waghmare UV, Sundaresan A, et al. (2013) Effect of co-substitution of nitrogen and fluorine in $\mathrm{BaTiO}_{3}$ on ferroelectricity and other properties. J Phys Condens Matter 25(34): 345901.

7. Wang X, Zhang Y, Song X, Yuan Z, Ma T, et al. (2012) Glass additive in barium titanate ceramics and its influence on electrical breakdown strength in relation with energy storage properties. J Eur Ceram Soc 32(3): 559-567.

8. Pedro SJ, Luis PM, Dia'inez JM, Antonio P, Criado JM (2010) Mechanochemical preparation of $\mathrm{BaTiO}_{3}-\mathrm{Ni}$ nanocomposites with high dielectric constant. Compos Struct 92(9): 2236-2240.

9. Nayak S, Sahoo B, Chaki TK, Khastgir D (2014) Facile preparation of uniform barium titanate (BaTiO3) multipods with high permittivity: impedance and temperature dependent dielectric behavior. RSC Adv 4(3): 1212-1224.

10. Kumar KS, Pittala S, Sanyadanam S, Paik P (2015) A new single/few-layered graphene oxide with a high dielectric constant of $10^{6}$ : contribution of defects and functional groups. RSC Adv 5(19): 14768-14779.

11. Zhou T, Zha JW, Cui RY, Fan BH, Yuan JK, et al. (2011) Improving dielectric properties of BaTiO3/ferroelectric polymer composites by employing surface hydroxylated $\mathrm{BaTiO}_{3}$ nanoparticles. ACS Appl Mater Interfaces 3(7): 21842188.

12. Li Y, Shi Y, Cai F, Xue J, Chen F, et al. (2015) Graphene sheets segregated by bariumtitanate for polyvinylidene fluoride composites with high dielectric constant and ultralow loss tangent. Composites Part A: Applied Science and Manufacturing 78: 318-326.

13. Yaqoob U, Uddin ASMI (2016) Chung GS The effect of reduced graphene oxide on the dielectric and ferroelectric properties of $\mathrm{PVDF}^{-\mathrm{BaTiO}_{3}}$ nanocomposites. RSC Adv 6(36): 30747-30754.

14. Shen Y, Guan Y, Hu Y, Lei Y, Song Y, et al. (2013) Dielectric behavior of graphene/ $\mathrm{BaTiO}_{3} /$ polyvinylidene fluoride nanocomposite under high electric field. Appl Phys Lett 103: 072906.

15. Wang D, Zhou T, Zha JW, Zhao J, Shi CY, et al. (2013) Functionalizedgraphene-BaTiO3/ferroelectric polymer Nano dielectric composites with high permittivity, low dielectric loss, and low percolation threshold. J Mater Chem A 1: 6162-6168.

16. Hummers WS, Offeman RE (1958) Preparation of graphitic oxide. J Am Chem Soc 80(6): 1339.

17. Xin CR, Zhang J, Liu Y, Zhang QL, Yang H, et al. (2013) Polymorphism and dielectric properties of Sc-doped $\mathrm{BaTiO}_{3}$ nanopowders synthesized by sol-gel method. Mater Res Bull 48(6): 2220-2226.

18. Wang RX, Zhu Q, Wang WS, Fan CM, Xu AW (2015) BaTiO3-graphenenanocomposites: synthesis and visible light photocatalytic activity. New J Chem 39(6): 4407-4413.

19. Mahata MK, Koppe T, Mondal T, Brusewitz C, Kumar $\mathrm{K}$, et al. (2015) Incorporation of $\mathrm{Zn} 2+$ ions into BaTiO3:Er3+/Yb3+ nanophosphor: an effective way to enhance upconversion, defect luminescence and temperature sensing. Phys Chem Chem Phys 17(32): 20741-20753.

20. Lu DY, Cheng W, Sun XY, Liu QL, Li DX, et al. (2014) Abnormal Raman spectra in Er-doped $\mathrm{BaTiO}_{3}$ ceramics. J Raman Spectrosc 45(10): 963-970.

21. Suchanicz J, Swierczek K, Nogas-Cwikiel E, Konieczny K, Sitko D (2015) PbMg1/3Nb2/303-doping effects on structural, thermal Raman, dielectric and ferroelectric properties of BaTiO3 ceramics. J Eur Ceram Soc 35(6): 1777-1783.

22. Yang D, Velamakanni A, Bozoklu G, Park S, Stoller M, et al. (2009) Chemical analysis of graphene oxide films after heat and chemical treatments by X-ray photoelectron and Micro-Raman spectroscopy. Carbon 47(1): 145-152.

23. Huang X, Zhi C, Jiang $\mathrm{P}$, Golberg D, Bando Y, et al. (2012) Temperature-dependent electrical property transition of graphene oxidepaper. Nanotechnology 23(45): 455705.

24. Adhlakha N, Yadav KL, Singh R (2014) Effect of $\mathrm{BaTiO}_{3}$ addition on structural, multiferroic and magneto-dielectric properties of $0.3 \mathrm{CoFe}_{2} \mathrm{O}_{4}$ - 


\section{Petroleum \& Petrochemical Engineering Journal}

0.7 $\mathrm{BiFeO}_{3}$ ceramics. Smart Mater Struct 23(10): 105024.

25. Li Y, Huang $X, \mathrm{Hu} Z$, Jiang P, Li S, et al. (2011) Large dielectric constant and high thermal conductivity in poly(vinylidene fluoride)/barium titanate/silicon carbide three-phase nanocomposites. ACS Appl Mater Interfaces 3(11): 4396-4403.

26. Wang B, Pu YP, Xu N, Wu HD, Chen K (2012) Dielectric properties of bariumtitanate-molybdenum composite. Ceram Int 38(Suppl 1): S37-S40.
27. Baryshnikov S, Stukova E, Koroleva E (2014) Dielectric properties of the ferroelectric composite $\left(\mathrm{NaNO}_{2}\right)_{0.9} /\left(\mathrm{BaTiO}_{3}\right)_{0.1}$. Compos B Eng 66: 190-193.

28. El-Nahass MM, Ali HAM (2012) Conductivity and dielectric behavior of bulk Furfurylidenemalononitrile. Solid State Commun 152(12): 1084-1088. 